Article

\title{
How Can Organizational Justice Contribute to Job Satisfaction? A Chained Mediation Model
}

\author{
Alessio Gori ${ }^{1}$, Eleonora Topino ${ }^{2}$, , Letizia Palazzeschi $^{3}$ and Annamaria Di Fabio ${ }^{3, * \mathbb{C}}$ \\ 1 Department of Health Sciences, University of Florence, Via di San Salvi, 12, Complesso di San Salvi, \\ Padiglione 26, 50135 Firenze FI, Italy; alessio.gori@unifi.it \\ 2 Department of Human Sciences, LUMSA University of Rome, Via della Traspontina 21, 00193 Rome, Italy; \\ eleonora.topino@gmail.com \\ 3 Department of Education, Languages, Intercultures, Literatures and Psychology (Psychology Section), \\ University of Florence, 50135 Firenze FI, Italy; letizia.palazzeschi@unifi.it \\ * Correspondence: adifabio@psico.unifi.it
}

Received: 7 September 2020; Accepted: 22 September 2020; Published: 24 September 2020

\begin{abstract}
The maintenance of workers' job satisfaction plays a central role among strategies supporting human capital, as it seems to be an important protective variable determining employees' well-being and individual and organizational performances. Thus, the aim of the present research was to analyze the contribution of different dispositional and organizational variables that could affect individual job satisfaction, particularly focusing on the direct and indirect effects of acceptance of change with the mediation of organizational justice and its subdimensions. A total of 179 Italian workers ( $41 \%$ men, $59 \%$ women; mean age $=47$ years old; $S D=10.87$ ) completed the Acceptance of Change Scale, Job Satisfaction Scale and Organizational Justice Scale. Results showed a significant influence of acceptance of change on job satisfaction, also highlighting a partial mediation effect of organizational justice. Furthermore, when the latter was explored in depth by considering its subdimensions (procedural, distributive, informational, interpersonal justice) as mediators, a significant chained total-mediation model emerged. Such findings can provide useful indications for research and intervention to favor workers' job satisfaction in several job contexts.
\end{abstract}

Keywords: chained mediation; job satisfaction; acceptance of change; organizational justice; procedural justice; distributive justice; informational justice; interpersonal justice

\section{Introduction}

Organizational success requires strategies to maintain high efficiency and productivity regarding performances of employees [1] on the one hand, and well-being of employees in a framework of healthy business and healthy organizations [2] on the other hand. This is particularly true in light of the high degrees of specialization and technologization of work required by the current word of work and globalization $[3,4]$. This scenario implies lasting and consistent attention to new strategies for renewal and updating $[5,6]$.

The maintenance of workers' job satisfaction plays a central and indispensable role among strategies supporting human capital [7]. Job satisfaction is traditionally considered "a pleasurable or positive emotional state resulting from the appraisal of one's job or job experience" ([8], p. 1300). It can be also considered in terms of the cognitive component of hedonic well-being in the work specific domain $[9,10]$. Several studies document the determining role of job satisfaction on happiness [11], quality of life [12] and physical and mental health [13] as well as with individual performances [14-17] and, consequently, organizational productiveness [18]. On the other hand, a state of dissatisfaction is 
frequently associated with turnover intentions [19], absenteeism [20,21], lower commitment [22] and poor job outcomes [23].

Furnham, Eracleous and Chamorro-Premuzic [24] pointed out the value of studying in depth both dispositional factors and organizational factors regarding job satisfaction. In line with this scenario, this research aimed to investigate the dispositional and organizational factors that could have an effect on individual job satisfaction, particularly focusing on acceptance of change and organizational justice.

First of all, the organizational maneuvers to maintain competitiveness in a dynamic and constantly evolving global market require employees to make a great effort to adapt and search for new strengths in the changing working context [25]. In light of this, a growing body of research focuses on the constructs concerning the individual disposition towards organizational change (see, for a review, [26,27]). Indeed, workers are the fulcrum of the realization of every change initiative, and their behaviors are the means by which these occur and persist (with greater or lesser success) over time, and their attitudes towards change may be considered a core predictor of their tendencies to resist or facilitate it [26]. Therefore, the centrality of the employee's acceptance of change stands out, which proves to be an important positive impact factor for the current working life [28] and represents a critical antecedent for the success of organizational change processes [29]. The construct of acceptance for change includes a range of aspects such as attitude, ability and positive dispositions towards change, constituting a functional key resource to face modern working challenges [30,31]. It expresses a positive predisposition that facilitates a sound approach to change, which is sought and seen as a source of learning, stimuli, growth and a resource to improve one's quality of life [28,32]. On the other hand, it also implies a positive reaction and effectiveness in managing difficulties and choices, being able to grasp the underlying social opportunity and supports and to flexibly switch between different decisions and concepts $[28,33]$. Therefore, in its various facets and components, the acceptance of change is closely linked to aspects such as well-being [28], relational civility [34] and job satisfaction [35].

Regarding organizational factors, among many constructs associated with job satisfaction, organizational justice has proven to play an important role, also in a cross-cultural perspective [36-38]. Evidence suggests that perceptions of fairness show a positive association with key attitudes and behaviors for organizational effectiveness, such as citizenship, commitment and higher performance [36,39-41], as well as a greater probability of successful organizational changes [42-45]. The construct of organizational justice [46] is well integrated with a vision of complexity and dynamism in the organizational context, as it consists not only of procedural (i.e., the process leading to decision outcomes [47]) and distributive (i.e., equity in the distribution of rewards; [48]) components, but also of interactional components [49]: informational justice (i.e., the correctness concerning honesty and timing of the information offered by the supervisors) and interpersonal justice (i.e., the quality of the interpersonal relationships regarding respect and sympathy demonstrated by supervisors). The four components of organizational justice emerged associated with different facets of working life [46,50]. In the agent-system model [46], procedural justice is able to predict system-referenced outcomes (e.g., rule compliance, group commitment), and interpersonal justice is able to predict agent-referenced outcomes (e.g., leader evaluation, helping). In the study by Cropanzano, Prehar and Chen [51], procedural and interactional justice showed different correlates: procedural justice with trust towards upper management and performance appraisal (PA) system satisfaction, and interactional justice with the fairness of the manager. Four decades of research regarding organizational justice across cultures showed that positive justice perceptions are linked to positive outcomes regarding both workers and organizations [39]. Finally, it was found to be significantly associated with several change dynamics, such as openness, satisfaction and commitment to change [52-54].

Given the above described theoretical framework, this study aimed to analyze the association of both dispositional and contextual factors in influencing job satisfaction, testing a single mediation and a chained mediation model in Italian workers. Two mediation models were elaborated. In the first one it was hypothesized that organizational justice mediates the association between acceptance of 
change and job satisfaction. In other words, following the Baron and Kenny [55] procedure, it was supposed that:

Step 1: Acceptance of change $(\mathrm{X})$ is associated with job satisfaction $(\mathrm{Y})$;

Step 2: Acceptance of change $(X)$ is related to organizational justice, the mediator variable $(\mathrm{M})$;

Step 3: Organizational justice $(\mathrm{M})$ influences job satisfaction $(\mathrm{Y})$.

This procedure can be used to evaluate if organizational justice mediates the relationship between acceptance of change and job satisfaction by analyzing the effect of acceptance of change on job satisfaction, controlling for organizational justice.

Then, a second hypothesized model deeply examined the contribution of organizational justice, by exploring the interaction of its subdimensions (procedural justice, distributive justice, informational justice, interpersonal justice) in mediating the relationship between acceptance of change and job satisfaction. Specifically, it was supposed that:

Step 1: Acceptance of change $(X)$ is associated with job satisfaction $(Y)$;

Step 2: Acceptance of change $(X)$ is related to one or more subdimensions of organizational justice (procedural justice, distributive justice, informational justice, interpersonal justice), the mediator variables $(\mathrm{M})$, which are linked in a chained way;

Step 3: One or more subdimensions of organizational justice (M) influence job satisfaction (Y).

This procedure can be used to assess if the subdimensions of organizational justice mediate the relationship between acceptance of change and job satisfaction through the analysis of the effect of acceptance of change on job satisfaction, controlling for the mediators.

\section{Method}

\subsection{Participants and Procedure}

The present research involved 179 participants ( $41 \%$ male and $59 \%$ female), with an average age of 47 years old ( $\mathrm{SD}=10.87$; age range $22-68$ years). Respondents were Italian workers belonging to several private Tuscan organizations. They voluntarily participated in the study and they did not have any form of compensation for their involvement in this research. All the participants were informed about the study general goal and completed the paper-pencil battery of self-report questionnaires only after they provided a written informed consent. The survey was administered by two qualified interviewers authorized to administer psychological tests. This study was carried out before the onset of the pandemic, the research protocol was implemented in line with the international ethics guidelines (World Medical Association, Helsinki, WMA) [56], and anonymity and privacy were granted.

\subsection{Measures}

\subsubsection{The Acceptance of Change Scale (AOC)}

The Acceptance of Change Scale (AOC) [28] assesses personal disposition towards changes and the tendency to embrace them. It consists of 20 items rated in a Likert response scale (from 1, which means "not at all", to 5, which means "a great deal"), grouped into 5 subdimensions: (1) predisposition to change (4 items), indicating the ability to learn and grow from changes (e.g., "When I am faced with a change, I can see things from multiple perspectives"); (2) support for change (4 items), indicating the perception of social support when facing changes (e.g., "I can compare myself with other people important to me when facing change"); (3) change seeking (4 items), indicating the tendency to search for changes and new stimuli (e.g., "Although I do not see the benefits, I cannot wait to change"); (4) positive reaction to change (4 items), indicating the tendency to feel positive emotion linked to changes, seen as positive experiences (e.g., "I am able to tolerate even the negative aspects of change"); (5) cognitive flexibility (4 items), indicating the mental ability to adapt to changes, easily modifying one's own outlines, plans and decisions (e.g., "It's easy for me to change my mind when I realize that I am wrong"). The Cronbach's alphas were: $\alpha=0.88$ for the total score, $\alpha=0.83$ for predisposition to 
change, $\alpha=0.79$ for support for change, $\alpha=0.80$ for change seeking, $\alpha=0.75$ for positive reaction to change and $\alpha=0.72$ for cognitive flexibility [28].

\subsubsection{The Job Satisfaction Scale (JSS)}

The Job Satisfaction Scale (JSS) [57] assesses the degree of feeling satisfaction with one's own current job. It includes 5 items (e.g., "Most days I am enthusiastic about my work") with a Likert response format from $1=$ "strongly disagree" to $7=$ "strongly agree". For the present research, the Italian version [58] was used, which showed a good internal consistency in the validation study $(\alpha=0.89)$.

\subsubsection{The Organizational Justice Scale (OJS)}

The Organizational Justice Scale (OJS) [46] assesses the perception concerning organizational justice. It comprises 20 items with a Likert response form, ranging from 1 ("lesser extent") to 5 ("greater extent"), grouped into 4 subdimensions: (1) distributive justice (4 items), concerning the perception of equity about the distribution of resources and rewards by the organization (e.g., "The evaluation of my performance provides a good assessment of the effort I have put into my work"); (2) procedural justice ( 7 items), concerning the perception of the organizational processes and fairness of procedures (e.g., "the procedures used in my organization are free of bias"); (3) interpersonal justice (4 items), concerning the perception of the courtesy shown to subordinates by supervisors (e.g., "My supervisor treats me in a polite manner"); (4) informational justice (5 items), concerning the perception of the correctness and truthfulness of the information offered by supervisors (e.g., "My supervisor communicates details in a timely manner"). In the validation study [59] the Italian version showed an excellent internal consistency, with Cronbach's $\alpha$ of the subscales ranging from 0.88 (interpersonal justice) to 0.93 (informational justice).

\subsection{Data Analysis}

The collected data were analyzed by using SPSS v. 25.0 for Windows. Descriptive statistics for all the analyzed variables and Pearson's correlations were calculated. The SPSS macro-program PROCESS v. 3.4 [60] was employed to test the hypothesized mediation models. The mediation analysis is a regression-based approach that can investigate how and if an independent variable $(X)$ exerts an effect on a dependent one, postulating the impact of one or more intervening variables (M) positioned between $X$ and $Y$; in other words, $M$ could be considered as the means by which $X$ has an influence on Y [60]. Therefore, a first single mediation (model 4) was created to analyze the effect of organizational justice on the association between acceptance of change and job satisfaction. Then, the impact of organizational justice was explored more deeply, considering its subdimensions, and a chained mediation (model 6) was created to assess the role of procedural justice, distributive justice, informational justice and interpersonal justice in mediating the association between acceptance of change and job satisfaction. Finally, the indirect effects were estimated. In this regard, the Sobel test (for the single mediation model only) and 95\% bootstrap confidence interval (based on 5000 resamples) were used. The first one determines the statistical significance of the mediation effect when the strength of the relationship between the antecedent and the outcome variables is significantly reduced after including the mediator in the model [55]. Although it has a high power cost, it is considered an excellent way to avoid type 1 error [60]. On the other hand, Hayes [60] emphasized the usefulness and power of the bootstrapping procedure in mediation analyses, which indicates the significance of the indirect effect when the zero was not included in the confidence interval (CI). 


\section{Results}

Descriptive statistics of the study variables and Pearson's correlations are reported in Table 1.

Table 1. Descriptive statistics of the variables and Pearson's correlations matrix.

\begin{tabular}{|c|c|c|c|c|c|c|c|c|c|c|c|c|c|}
\hline & 1 & 2 & 3 & 4 & 5 & 6 & 7 & 8 & 9 & 10 & 11 & $M$ & $S D$ \\
\hline 1. JSS & 1 & & & & & & & & & & & 22.89 & 5.30 \\
\hline 2. $\mathrm{AOC}$ & $0.282 * *$ & 1 & & & & & & & & & & 66.93 & 10.01 \\
\hline 3. $\mathrm{AOC}(\mathrm{F} 1)$ & $0.250 * *$ & $0.807^{* *}$ & 1 & & & & & & & & & 13.37 & 2.86 \\
\hline 4. AOC (F2) & $0.487^{* *}$ & $0.684^{* *}$ & $0.456^{* *}$ & 1 & & & & & & & & 14.73 & 2.55 \\
\hline 5. AOC (F3) & -0.80 & $0.566^{* *}$ & 0.298 ** & 0.060 & 1 & & & & & & & 11.17 & 3.61 \\
\hline 6. AOC (F4) & $0.369 * *$ & $0.789 * *$ & $0.669 * *$ & $0.642 * *$ & $0.182 *$ & 1 & & & & & & 13.6 & 2.72 \\
\hline 7. AOC (F5) & 0.058 & $0.661^{* *}$ & $0.431^{* *}$ & 0.381 ** & $0.206^{* *}$ & 0.360 ** & 1 & & & & & 14.05 & 2.68 \\
\hline 8. OJS & $0.519 * *$ & $0.292 * *$ & $0.303^{* *}$ & $0.317^{* *}$ & -0.022 & $0.346^{* *}$ & 0.145 & 1 & & & & 69.05 & 12.94 \\
\hline 9. OJS(F1) & $0.333^{* *}$ & $0.164 *$ & $0.212 * *$ & $0.152 *$ & -0.047 & $0.189^{*}$ & 0.113 & $0.802 * *$ & 1 & & & 22.15 & 6.18 \\
\hline 10. OJS (F2) & $0.427^{* *}$ & $0.283^{* *}$ & $0.280 * *$ & $0.364^{* *}$ & -0.082 & $0.381 * *$ & 0.135 & $0.715^{* *}$ & $0.413^{* *}$ & 1 & & 13.65 & 3.89 \\
\hline 11. OJS (F3) & $0.415^{* *}$ & $0.282 * *$ & $0.267^{* *}$ & $0.282 * *$ & 0.015 & $0.248^{* *}$ & $0.227^{* *}$ & $0.672 * *$ & $0.321 * *$ & $0.336^{* *}$ & 1 & 15.00 & 3.20 \\
\hline 12. OJS (F4) & $0.424^{* *}$ & $0.187^{*}$ & $0.168 *$ & $0.205^{* *}$ & 0.056 & $0.245 *$ & 0.001 & $0.789 * *$ & $0.441^{* *}$ & $0.444^{* *}$ & $0.575^{* *}$ & 17.96 & 4.00 \\
\hline
\end{tabular}

Note: ${ }^{* *}$ Correlation is significant at the 0.01 level (2-tailed); ${ }^{*}$ correlation is significant at the 0.05 level (2-tailed). JSS = Job Satisfaction Scale; AOC = acceptance of change; AOC (F1) = predisposition to change; $\mathrm{AOC}(\mathrm{F} 2)=$ support for change; $\mathrm{AOC}(\mathrm{F} 3)=$ change seeking; $\mathrm{AOC}(\mathrm{F} 4)=$ positive reaction to change; AOC (F5) = cognitive flexibility; OJS = Organizational Justice Scale; OJS (F1) = distributive justice; OJS (F2) = procedural justice; OJS (F3) = interpersonal justice; OJS (F4) = informative justice.

Results showed that acceptance of change had a significant and positive influence on job satisfaction (see Figures 1 and 2; path $c, \beta=0.28, p<0.001$ ). The single mediation model also indicated that acceptance of change was positively and significantly related to organizational justice (Figure 1; path $a, \beta=0.29, p<0.001$ ), which in turn positively affected job satisfaction (Figure $1 ;$ path $b, \beta=0.48$, $p<0.001$ ). Nevertheless, the direct effect of acceptance of change on job satisfaction (path $c^{\prime}$ in Figure 1) was still significant, albeit reduced, after controlling organizational justice, suggesting a partial mediation $\left(R^{2}=0.288, F_{2,176}=35.592, p<0.001\right)$. The statistical significance of this model and its indirect effect were confirmed by both the bootstrapping procedure (boot Lower Limit Confidence Interval $[\mathrm{LLCI}]=0.036$; boot Upper Limit Confidence Interval $[\mathrm{ULCI}]=0.117$ ) and the Sobel test $(z=2.28, p<0.05)$.

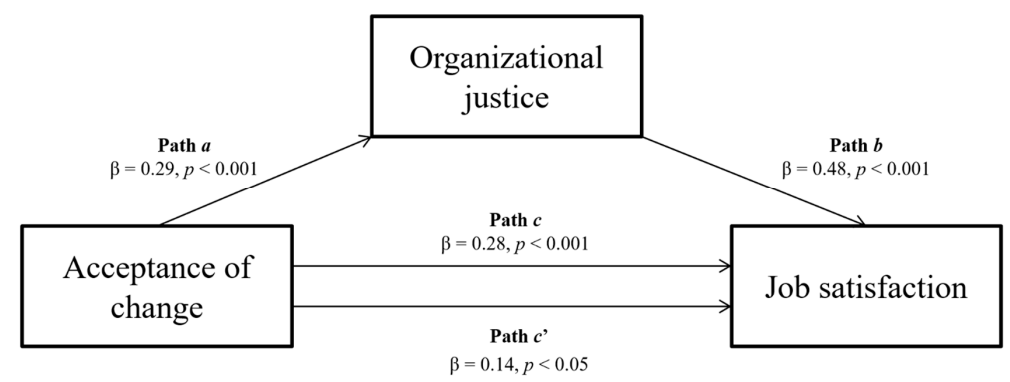

Figure 1. Single mediation model.

The chained mediation brought to light the role of the various organizational change subscales in the indirect path between acceptance of change and job satisfaction.

Indeed, acceptance of change significantly affected procedural justice (Figure 2; path $a_{1}, \beta=0.28$, $p<0.001$ ), which impacted distributive justice (Figure 2; path $a_{3}, \beta=0.40, p<0.001$ ), which affected informational justice (Figure 2; path $a_{6}, \beta=0.31, p<0.001$ ), which, in turn, affected interpersonal justice (path $a_{10}$ in Figure $2 ; \beta=0.50, p<0.001$ ), which, ultimately, impacted job satisfaction (Figure 2; path $b_{4}$, $\beta=0.19, p<0.05)$. The latter also suffered the direct effect of the first mediator, procedural justice (Figure 2; path $b_{1}, \beta=0.22, p<0.01$ ), which in turn influenced informational justice, the third mediator (Figure 2; path $a_{5}, \beta=0.30, p<0.001$ ). Acceptance of change also positively influenced interpersonal justice (Figure 2; path $a_{7}, \beta=0.17, p<0.01$ ), and its direct effect on job satisfaction (path $c^{\prime}$ in Figure 2) was not significant after controlling the mediators $(\beta=0.12, p=0.073)$, indicating a complete mediation (Table $2 ; R^{2}=0.304, F_{5,173}=15.086, p<0.001$ ). 
Table 2. Chained mediation model coefficients.

\begin{tabular}{|c|c|c|c|c|c|c|c|c|c|c|c|c|c|c|c|c|c|c|c|c|}
\hline \multirow[b]{3}{*}{ Antecedent } & \multicolumn{20}{|c|}{ Consequent } \\
\hline & & \multicolumn{3}{|c|}{ M1 } & \multicolumn{4}{|c|}{ M2 } & & \multicolumn{3}{|c|}{ M3 } & \multicolumn{5}{|c|}{ M4 } & \multicolumn{3}{|c|}{$\mathbf{Y}$} \\
\hline & & Coeff. & SE & $p$ & & Coeff. & SE & $p$ & & Coeff. & SE & $p$ & & Coeff. & SE & $p$ & & Coeff. & SE & $p$ \\
\hline$X$ & $a_{1}$ & 0.110 & 0.028 & $<0.001$ & $a_{2}$ & 0.032 & 0.044 & 0.472 & $a_{4}$ & 0.021 & 0.027 & 0.445 & $a_{7}$ & 0.053 & 0.020 & $<0.01$ & $c^{\prime}$ & 0.065 & 0.036 & 0.073 \\
\hline M1 & & - & - & - & $a_{3}$ & 0.634 & 0.114 & $<0.001$ & $a_{5}$ & 0.311 & 0.075 & $<0.001$ & $a_{8}$ & 0.037 & 0.059 & 0.534 & $b_{1}$ & 0.305 & 0.103 & 0.003 \\
\hline M2 & & - & - & - & & - & - & - & $a_{6}$ & 0.199 & 0.046 & $<0.001$ & $a_{9}$ & 0.028 & 0.036 & 0.438 & $b_{2}$ & 0.080 & 0.063 & 0.210 \\
\hline M3 & & - & - & - & & - & - & - & & - & - & - & $a_{10}$ & 0.400 & 0.057 & $<0.001$ & $b_{3}$ & 0.202 & 0.112 & 0.074 \\
\hline M4 & & - & - & - & & - & - & - & & - & - & - & & - & - & - & $b_{4}$ & 0.312 & 0.132 & 0.019 \\
\hline \multirow[t]{2}{*}{ Constant } & $i_{M 1}$ & 6.283 & 1.895 & 0.001 & $i_{M 2}$ & 11.368 & 2.950 & $<0.001$ & $i_{M 3}$ & 7.931 & 1.861 & $<0.001$ & $i_{M 4}$ & 3.362 & 1.473 & $<0.05$ & $i_{Y}$ & 4.258 & 2.603 & 0.104 \\
\hline & \multicolumn{4}{|c|}{$\begin{array}{c}R^{2}=0.080 \\
7)=14.401, p\end{array}$} & \multicolumn{4}{|c|}{$\begin{array}{c}R^{2}=0.173 \\
76)=18.453, p\end{array}$} & \multicolumn{4}{|c|}{$\begin{array}{c}R^{2}=0.280 \\
765)=22.639, p\end{array}$} & \multicolumn{4}{|c|}{$\begin{array}{c}R^{2}=0.366 \\
174)=25.159, p\end{array}$} & \multicolumn{4}{|c|}{$\begin{array}{c}R^{2}=0.304 \\
3)=15.086, p\end{array}$} \\
\hline
\end{tabular}

Note: $\mathrm{X}=$ Acceptance of change; $\mathrm{M} 1$ = procedural justice; $\mathrm{M} 2$ = distributive justice; $\mathrm{M} 3$ = informational justice; $\mathrm{M} 4$ = interpersonal justice; $\mathrm{Y}=$ job satisfaction. 


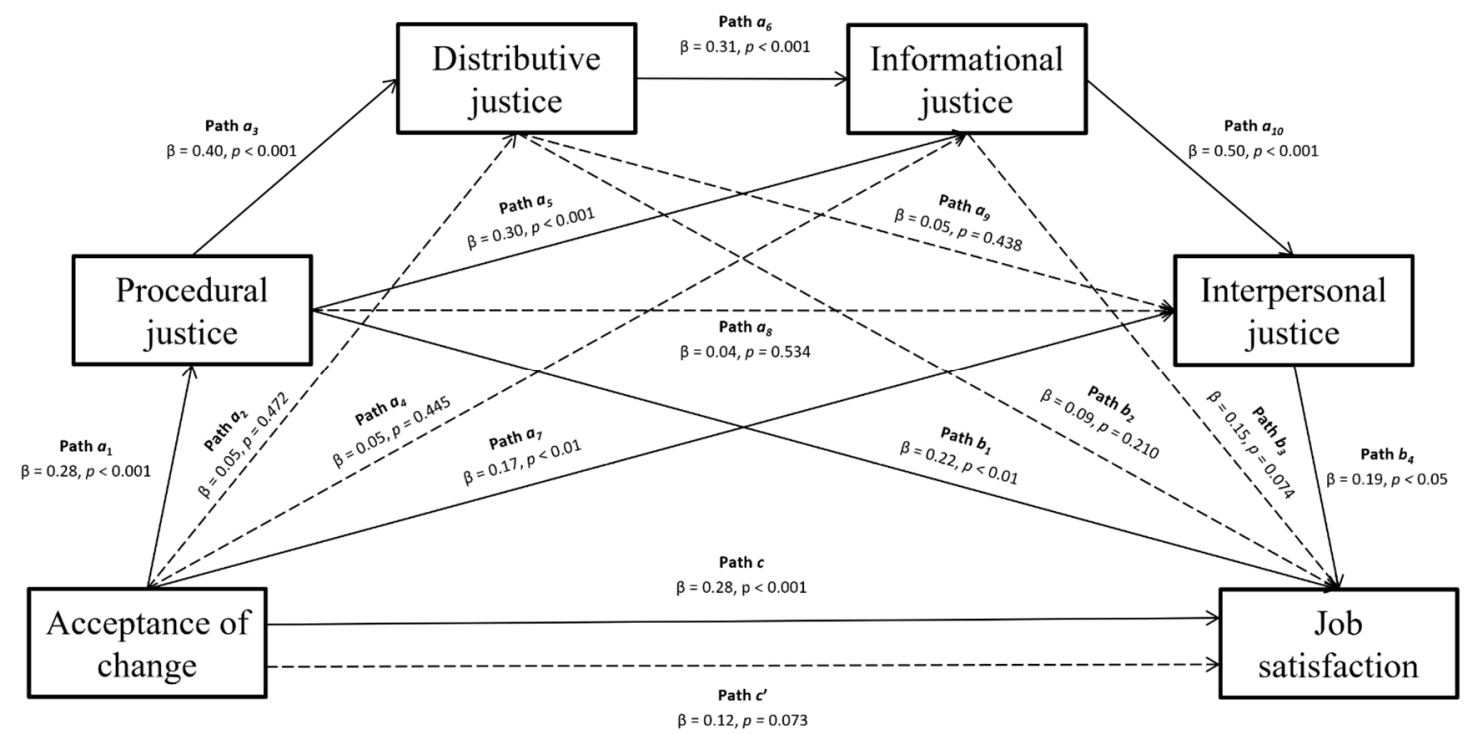

Figure 2. Chained mediation model.

Finally, the bootstrapping procedure confirmed the statistical significance of this chained mediation and its indirect effect (boot LLCI $=0.040$; boot ULCI $=0.134$ ).

All the models' effects indices are reported in Table 3.

Table 3. Models' effects indices.

\begin{tabular}{ccccccccc}
\hline \multirow{2}{*}{ Model } & $\begin{array}{c}\text { Total } \\
\text { Effect }\end{array}$ & $\begin{array}{c}\text { Direct } \\
\text { Effect }\end{array}$ & $\begin{array}{l}\text { Indirect } \\
\text { Effect }\end{array}$ & $\begin{array}{c}\text { Partial Standardized } \\
\text { Indirect Effect }\end{array}$ & $\begin{array}{c}\text { Completely } \\
\text { Standardized Indirect } \\
\text { Effect }\end{array}$ & $\begin{array}{c}\text { Bootstrapping } \\
\text { 95\% CI }\end{array}$ & \multicolumn{2}{c}{ Sobel Test } \\
\hline Model 1 & 0.15 & 0.08 & 0.07 & 0.01 & 0.15 & $(0.036,0.117)$ & 2.28 & sign \\
\hline Model 2 & 0.15 & 0.06 & 0.08 & 0.02 & 0.16 & $(0.040,0.134)$ & - \\
\hline
\end{tabular}

Note: Model 1 = the single mediation of organizational justice in relationship between acceptance of change and job satisfaction; Model 2 = the mediation of procedural justice, distributive justice, informational justice and interpersonal justice in the relationship between acceptance of change and job satisfaction.

\section{Discussion}

Globalization and the rapid economic changes of the post-modern era offer organizations numerous opportunities for growth but also imply great challenges that are reflected in the substantial requests for adaptation, flexibility and dynamic competence to workers [3]. In this context, job satisfaction appears to be an important protective variable, since it is connected both to individual well-being [61] and to organizational commitment [62]. Given these important premises, the aims of the present research were to investigate the relationship between acceptance of change and job satisfaction and the mediation role of organizational justice, and to deeply analyze the influences of acceptance of change, perception of organizational justice and its subdimensions in job satisfaction.

As regards to the first hypothesis, the single mediation model indicated that acceptance of change was positively and significantly related to organizational justice, suggesting a partial mediation.

These results can be considered in line with previous research [43] where lower levels of acceptance of change were related to less job satisfaction. Moreover, significant indirect paths were identified in this relationship. Firstly, the positive mediation effect of perceived organizational justice was highlighted, confirming evidence that fair treatment is associated with favorable attitudes towards work and higher job performance [40,63]. These data are particularly important in light of previous research that highlighted that fairness concerns emerge significantly in times of organizational changes [64] and that the impact of the latter on job satisfaction could be mediated by organizational trust [65]. Therefore, the obtained results could broaden this picture, indicating that acceptance of change could be interpreted as a form of openness that enables workers to remain positively disposed in confidently 
perceiving higher levels of organizational justice, and this, in turn, could positively influence the levels of satisfaction.

As regards to the second chained mediation model, which deepened knowledge of the organizational justice construct, the data also showed an indirect path with its subdimensions: procedural, distributive, informational and interpersonal justice. Specifically, acceptance of change affected the perception of fairness for rewards distribution procedures, which had an effect on the feeling that these are equally distributed. Justice in these two situations, in turn, influenced the perception of having correct information and therefore of being treated with dignity by supervisors, favoring job satisfaction. Interestingly, when all these dimensions of organizational justice were combined in the indirect path, the direct one of acceptance of change on job satisfaction became insignificant, highlighting the importance of contextual variables and organizational characteristics in promoting this canal [66-68] and therefore opening the door to a wide range of possible organizational interventions on these factors to encourage worker satisfaction. Furthermore, among the others, procedural and interpersonal justice not only interacted with the other factors in the chain but they were also the aspects most strongly influenced by acceptance of change, which most affected job satisfaction. This, on the one hand, underlines the importance of organizational justice [69] and, on the other hand, reinforces the possibility that greater acceptance of change can maintain a positive openness to environmental stimuli [70], facilitating the perception of positive and supportive relationships [35].

This research has several limitations that should be addressed. Firstly, the cross-sectional nature of the study hinders the precise detection of cause-effect relationships. Future studies should employ a longitudinal perspective to confirm and/or extend our results. Furthermore, the use of self-reported measures for collecting data could determine reporting biases, such as the desirability. In future research, the use of a multimodal approach could be used to overcome this issue. Moreover, this research involved only employees of private organizations, and this aspect limits the generalizability of results to other job contexts. It could be an interesting challenge for future research to explore differences between public and private as well as for-profit and non-profit organizations. Furthermore, this study was conducted before the pandemic, and thus these results did not consider it. It would be useful to investigate these relationships during the period of the pandemic or after it has finished. Finally, future research could also examine the differences among the various kinds of work activity, considering, for example, the high risk of psychological distress and symptoms for the healthcare professions, as evidenced by the scientific literature (see, for a review, Johnson et al. [71]).

\section{Conclusions}

This research contributes to a greater comprehension of the interaction of some dispositional and contextual factors in favoring workers' positive outcomes, as well as job satisfaction, a relevant outcome given the current complex world of work. In light of the importance of the employees' attitudes towards their jobs in promoting organizational outcomes [72-74], these data can provide useful indications for interventions in several job contexts. Specifically, this study shows the contribution of organizational justice and, in particular, of its subdimensions in mediating the relationship between acceptance of change and job satisfaction, pointing out some practical implications. Indeed, such findings highlight the utility to intervene in the organizational context to improve workers' perceptions of fairness, with particular focus on procedural and interpersonal justice. This provides further evidence to support the weight of supportive supervisors and clear job descriptions to avoid ambiguity and conflict [75], suggesting the importance of some human resource management practices (e.g., bottom-up information) aimed at increasing the perception of procedural justice [76], in combination with a leadership training [77]. On the other hand, acceptance of change could also be a focus for organizational interventions, operating both directly with a training aimed at the development of this personal factor [78] and indirectly by favoring the contextual conditions in which it emerges (e.g., positive organizational culture and climate $[7,26])$. 
In summary, with respect to job satisfaction, these results underline the importance to intervene in acceptance of change, which is a dispositional characteristic amenable to training [28] on one hand; on the other hand, they highlight the possibility to intervene by improving the contextual characteristics of the working environment, acting above all on procedural and interpersonal justice.

Author Contributions: Conceptualization: A.G. and A.D.F.; Data curation: A.G., E.T., L.P. and A.D.F.; Investigation: A.G., E.T., L.P. and A.D.F.; Methodology: A.G. and A.D.F.; Writing original draft: A.G., E.T., L.P. and A.D.F.; Review and editing: A.G., E.T., L.P. and A.D.F. All authors have read and agree to the published version of the manuscript.

Funding: This research received no external funding.

Conflicts of Interest: The authors declare no conflict of interest.

\section{References}

1. Dessler, G. Fundamentals of Human Resource Management; Pearson Higher Education: New York, NY, USA, 2011.

2. Di Fabio, A. Positive Healthy Organizations: Promoting Well-Being, Meaningfulness, and Sustainability in Organizations. Front. Psychol. 2017, 8, 1938. [CrossRef] [PubMed]

3. Blustein, D.L.; Kenny, M.E.; Di Fabio, A.; Guichard, J. Expanding the impact of the psychology of working: Engaging pychology in the struggle for decent work and human rights. J. Career Assess. 2018, 27, 3-28. [CrossRef]

4. Duffy, R.D.; Blustein, D.L.; Diemer, M.A.; Autin, K.L. The psychology of working theory. J. Couns. Psychol. 2016, 63, 127-148. [CrossRef] [PubMed]

5. Kašpárková, L.; Vaculik, M.; Prochazka, J.; Schaufeli, W.B. Why resilient workers perform better: The roles of job satisfaction and work engagement. J. Work. Behav. Health 2018, 33, 43-62. [CrossRef]

6. Peiró, J.M.; Bayona, J.A.; Caballer, A.; Di Fabio, A. Importance of work characteristics affects job performance: The mediating role of individual dispositions on the work design-performance relationships. Pers. Individ. Differ. 2020, 157, 109808. [CrossRef]

7. Di Fabio, A.; Peiró, J.M. Human Capital Sustainability Leadership to Promote Sustainable Development and Healthy Organizations: A New Scale. Sustainability 2018, 10, 2413. [CrossRef]

8. Locke, E.A. The Nature and Causes of Job satisfaction. In Handbook of Industrial and Organizational Psychology; Dunnette, M.D., Ed.; Rand McNally: Chicago, IL, USA, 1976; pp. 1297-1349.

9. Fisher, C. Conceptualizing and measuring wellbeing at work. Wellbeing 2014, 1-25. [CrossRef]

10. Sirgy, M.J. The Psychology of Quality of Life; Springer Science and Business Media LLC: Berlin, Germany, 2012; Volume 50.

11. Brown, D.; McIntosh, S. Job satisfaction in the low wage service sector. Appl. Econ. 2003, 35, 1241-1254. [CrossRef]

12. Cimete, G.; Gencalp, N.S.; Keskin, G. Quality of Life and Job Satisfaction of Nurses. J. Nurs. Care Qual. 2003, 18, 151-158. [CrossRef]

13. Faragher, E.B.; Cass, M.; Cooper, C.L. The Relationship between Job Satisfaction and Health: A Meta-Analysis. In From Stress to Wellbeing Volume 1; Springer Science and Business Media LLC: Berlin, Germany, 2013; Volume 1, pp. 254-271.

14. Ayala, Y.; Peiró, J.M.; Tordera, N.; Lorente, L.; Yeves, J. Job satisfaction and innovative performance in young Spanish employees: Testing new patterns in the happy-productive worker thesis-A Discriminant Study. J. Happiness Stud. 2016, 18, 1377-1401. [CrossRef]

15. Bayona, J.A.; Caballer, A.; Peiró, J.M. The Relationship between knowledge characteristics' fit and job satisfaction and job performance: The mediating role of work engagement. Sustainability 2020, 12, 2336. [CrossRef]

16. Judge, T.A.; Thoresen, C.J.; Bono, J.E.; Patton, G.K. The job satisfaction-job performance relationship: A qualitative and quantitative review. Psychol. Bull. 2001, 127, 376-407. [CrossRef] [PubMed]

17. Roberts, J.A.; David, M.E. Boss phubbing, trust, job satisfaction and employee performance. Pers. Individ. Differ. 2020, 155, 109702. [CrossRef]

18. Miah, M. The impact of employee job satisfaction toward organizational performance: A study of private sector employees in Kuching, East Malaysia. Int. J. Sci. Res. Publ. (IJSRP) 2018, 8, 270-278. [CrossRef] 
19. Gillet, N.; Fouquereau, E.; Coillot, H.; Cougot, B.; Moret, L.; Dupont, S.; Bonnetain, F.; Colombat, P. The effects of work factors on nurses' job satisfaction, quality of care and turnover intentions in oncology. J. Adv. Nurs. 2018, 74, 1208-1219. [CrossRef] [PubMed]

20. Schaumberg, R.L.; Flynn, F.J. Clarifying the link between job satisfaction and absenteeism: The role of guilt proneness. J. Appl. Psychol. 2017, 102, 982-992. [CrossRef]

21. Thirulogasundaram, V.; Sahu, P. Job satisfaction and absenteeism interface in corporate sector-A study. IOSR J. Humanit. Soc. Sci. 2014, 19, 64-68. [CrossRef]

22. Ćulibrk, J.; Delic, M.; Mitrović, S.; Ćulibrk, D. Job satisfaction, organizational commitment and job involvement: The mediating role of job involvement. Front. Psychol. 2018, 9, 132. [CrossRef]

23. Harter, J.K.; Schmidt, F.L. Well-being in the workplace and its relationship to business outcomes: A review of the Gallup studies. In Flourishing: Positive Psychology and the Life Well-Lived; American Psychological Association (APA): Washington, DC, USA, 2004; pp. 205-224.

24. Furnham, A.; Eracleous, A.; Chamorro-Premuzic, T. Personality, motivation and job satisfaction: Hertzberg meets the Big Five. J. Manag. Psychol. 2009, 24, 765-779. [CrossRef]

25. Ford, J.D.; Ford, L.W.; D'Amelio, A. resistance to change: The rest of the story. Acad. Manag. Rev. 2008, 33, 362-377. [CrossRef]

26. Choi, M. Employees' attitudes toward organizational change: A literature review. Hum. Resour. Manag. 2011, 50, 479-500. [CrossRef]

27. Dunican, B. Acceptance of Change: Exploring the Relationship among Psychometric Constructs and Employee Resistance. Ph.D. Thesis, Western Kentucky University, Bowling Green, KY, USA, 2015.

28. Di Fabio, A.; Gori, A. Developing a New Instrument for Assessing Acceptance of Change. Front. Psychol. 2016, 7, 802. [CrossRef] [PubMed]

29. Nielsen, K.; Randall, R. The importance of employee participation and perceptions of changes in procedures in a teamworking intervention. Work. Stress 2012, 26, 91-111. [CrossRef] [PubMed]

30. Kavanagh, M.H.; Ashkanasy, N.M. The impact of leadership and change management strategy on organizational culture and individual acceptance of change during a merger. Br. J. Manag. 2006, 17, S81-S103. [CrossRef]

31. Heuvel, M.V.D.; Demerouti, E.; Bakker, A.B.; Schaufeli, W. Adapting to change: The value of change information and meaning-making. J. Vocat. Behav. 2013, 83, 11-21. [CrossRef]

32. Deci, E.L.; Ryan, R.M. The "What" and "Why" of goal pursuits: Human needs and the self-determination of behavior. Psychol. Inq. 2000, 11, 227-268. [CrossRef]

33. Fredrickson, B.L. The role of positive emotions in positive psychology: The broaden-and-build theory of positive emotions. Am. Psychol. 2001, 56, 218-226. [CrossRef]

34. Di Fabio, A.; Gori, A. Assessing workplace relational civility (WRC) with a new multidimensional "mirror" measure. Front. Psychol. 2016, 7, 890. [CrossRef]

35. Gori, A.; Topino, E. Predisposition to change is linked to job satisfaction: Assessing the mediation roles of workplace relation civility and insight. Int. J. Environ. Res. Public Health 2020, 17, 2141. [CrossRef]

36. Colquitt, J.A.; Conlon, D.E.; Wesson, M.J.; Porter, C.O.L.H.; Ng, K.Y. Justice at the millennium: A meta-analytic review of 25 years of organizational justice research. J. Appl. Psychol. 2001, 86, 425-445. [CrossRef]

37. Lu, H.; Zhao, Y.; While, A. Job satisfaction among hospital nurses: A literature review. Int. J. Nurs. Stud. 2019, 94, 21-31. [CrossRef] [PubMed]

38. Silva, M.R.; Caetano, A. Organizational justice across cultures: A systematic review of four decades of research and some directions for the future. Soc. Justice Res. 2016, 29, 257-287. [CrossRef]

39. Cohen-Charash, Y.; Spector, P.E. The role of justice in organizations: A meta-analysis. Organ. Behav. Hum. Decis. Process. 2001, 86, 278-321. [CrossRef]

40. Gilliland, S.W. Effects of procedural and distributive justice on reactions to a selection system. J. Appl. Psychol. 1994, 79, 691-701. [CrossRef]

41. Mylona, E.; Mihail, D. Enhancing employees' work performance through organizational justice in the context of financial crisis. A study of the Greek public sector. Int. J. Public Adm. 2018, 42, 509-519. [CrossRef]

42. Foster, R.D. Resistance, justice, and commitment to change. Hum. Resour. Dev. Q. 2010, 21, 3-39. [CrossRef]

43. Greenberg, J. Setting the justice agenda: Seven unanswered questions about "what, why, and how". J. Vocat. Behav. 2001, 58, 210-219. [CrossRef] 
44. Wanberg, C.R.; Banas, J.T. Predictors and outcomes of openness to changes in a reorganizing workplace. J. Appl. Psychol. 2000, 85, 132-142. [CrossRef]

45. Stouten, J.; Rousseau, D.M.; De Cremer, D. Successful oganizational change: Integrating the management practice and scholarly literatures. Acad. Manag. Ann. 2018, 12, 752-788. [CrossRef]

46. Colquitt, J.A. On the dimensionality of organizational justice: A construct validation of a measure. J. Appl. Psychol. 2001, 86, 386-400. [CrossRef]

47. Thibaut, J.W.; Walker, L. Procedural Justice A Psychological Analysis; Lawrence Erlbaum Associates: Hillsdale, MI, USA, 1975.

48. Adams, J.S. Inequity in Social Exchange. In Advances in Experimental Social Psychology; Elsevier BV: Amsterdam, The Netherlands, 1965; Volume 2, pp. 267-299.

49. Bies, R.J.; Moag, J.F. Interactional justice: Communication criteria of fairness. In Research on Negotiations in Organizations; Lewicki, R.J., Sheppard, B.H., Bazerman, M.H., Eds.; JAI Press: Greenwich, CT, USA, 1986; pp. 43-55.

50. Colquitt, J.A. Organizational justice. Organ. Justice 2012, 1, 526-547. [CrossRef]

51. Cropanzano, R.; Prehar, C.A.; Chen, P.Y. Using social exchange theory to distinguish procedural from interactional justice. Group Organ. Manag. 2002, 27, 324-351. [CrossRef]

52. Blader, S.L.; Tyler, T.R. How can theories of organizational justice explain the effects of fairness? In Handbook of Organizational Justice; Greenberg, J., Colquitt, J.A., Eds.; Lawrence Erlbaum Associates: Mahwah, NJ, USA, 2005; pp. 329-354.

53. Kool, M.; Van Dierendonck, D. Servant leadership and commitment to change, the mediating role of justice and optimism. J. Organ. Chang. Manag. 2012, 25, 422-433. [CrossRef]

54. Paolillo, A.; Platania, S.; Magnano, P.; Ramaci, T. Organizational justice, optimism and commitment to change. Procedia-Soc. Behav. Sci. 2015, 191, 1697-1701. [CrossRef]

55. Baron, R.M.; Kenny, D.A. The moderator-mediator variable distinction in social psychological research: Conceptual, strategic, and statistical considerations. J. Pers. Soc. Psychol. 1986, 51, 1173-1182. [CrossRef]

56. World Medical Association Declaration of Helsinki. JAMA 2013, 310, 2191-2194. [CrossRef]

57. Judge, T.A.; Locke, E.A.; Durham, C.C.; Kluger, A.N. Dispositional effects on job and life satisfaction: The role of core evaluations. J. Appl. Psychol. 1998, 83, 17-34. [CrossRef]

58. Di Fabio, A. Job Satisfaction Scale: Primo Contributo alla validazione della Versione Italiana [Job Satisfaction Scale: First Contribution to the Validation of the Italian Version]. G. Ital. Ric. Appl. Italy 2018, 11. [CrossRef]

59. Di Fabio, A. Strumenti per il Counseling Organizzativo: Proprietà Psicometriche della Versione Italiana dell'Organizational Justice Scale (OJS) [Instrument for the Organizational Counseling: Psychometric Properties of the Italian Version of the Organizational Justice Scale]. Couns. G. Ital. Ric. Appl. 2008, 1, 209-223.

60. Hayes, A.F. Introduction to Mediation, Moderation, and Conditional Process. Analysis: A Regression-Based Approach, 2nd ed.; Guilford Press: New York, NY, USA, 2018.

61. Warr, P. Work, Happiness, and Unhappiness; Psychology Press: London, UK, 2011.

62. Srivastava, S. Job satisfaction and organizational commitment relationship: Effect of personality variables. Vis. J. Bus. Perspect. 2013, 17, 159-167. [CrossRef]

63. Konovsky, M.A. Understanding procedural justice and its impact on business organizations. J. Manag. 2000, 26, 489-511. [CrossRef]

64. Cobb, A.T.; Wooten, K.C.; Folger, R. Justice in the making: Toward understanding the theory and practice of justice in organizational change and development. Res. Organ. Chang. Dev. 1995, 8, 243-295.

65. Gupta, S.; Singla, A. Organizational change and job satisfaction: An analysis of mediating effect of organizational trust. Indian J. Commer. Manag. Stud. 2016, 7, 7-13.

66. Judge, T.A.; Kammeyer-Mueller, J.D. Job attitudes. Annu. Rev. Psychol. 2012, 63, 341-367. [CrossRef]

67. Dal Corso, L.; Carluccio, F.; Buonomo, I.; Benevene, P.; Vecina, M.; West, M. "I that is we, we that is I": The mediating role of work engagement between key leadership behaviors and volunteer satisfaction. Test. Psychom. Methodol. Appl. Psychol. 2019, 26, 561-572.

68. Raziq, A.; Maulabakhsh, R. Impact of working environment on job satisfaction. Procedia Econ. Financ. 2015, 23, 717-725. [CrossRef]

69. Clay-Warner, J.; Reynolds, J.; Roman, P. Organizational justice and job satisfaction: A test of three competing models. Soc. Justice Res. 2005, 18, 391-409. [CrossRef] 
70. Gori, A.; Craparo, G.; Giannini, M.; Loscalzo, Y.; Caretti, V.; La Barbera, D.; Manzoni, G.M.; Castelnuovo, G.; Tani, F.; Ponti, L.; et al. Development of a new measure for assessing insight: Psychometric properties of the insight orientation scale (IOS). Schizophr. Res. 2015, 169, 298-302. [CrossRef]

71. Johnson, J.; Hall, L.H.; Berzins, K.; Baker, J.; Melling, K.; Thompson, C. Mental healthcare staff well-being and burnout: A narrative review of trends, causes, implications, and recommendations for future interventions. Int. J. Ment. Health Nurs. 2017, 27, 20-32. [CrossRef]

72. Gracia, F.J.; Ramos, J.; Peiró, J.M.; Caballer, A.; Sora, B. Job attitudes, behaviours and well-being among different types of temporary workers in Europe and Israel. Int. Labour Rev. 2011, 150, 235-254. [CrossRef]

73. Giorgi, G.; Shoss, M.K.; Leon-Perez, J.M. Going beyond workplace stressors: Economic crisis and perceived employability in relation to psychological distress and job dissatisfaction. Int. J. Stress Manag. 2015, 22, 137-158. [CrossRef]

74. Ostroff, C. The relationship between satisfaction, attitudes, and performance: An organizational level analysis. J. Appl. Psychol. 1992, 77, 963-974. [CrossRef]

75. St-Pierre, I.; Holmes, D. The relationship between organizational justice and workplace aggression. J. Adv. Nurs. 2010, 66, 1169-1182. [CrossRef] [PubMed]

76. Tremblay, M.; Cloutier, J.; Simard, G.; Chênevert, D.; Vandenberghe, C. The role of HRM practices, procedural justice, organizational support and trust in organizational commitment and in-role and extra-role performance. Int. J. Hum. Resour. Manag. 2010, 21, 405-433. [CrossRef]

77. Miao, C.; Humphrey, R.H.; Qian, S. Leader emotional intelligence and subordinate job satisfaction: A meta-analysis of main, mediator, and moderator effects. Pers. Individ. Differ. 2016, 102, 13-24. [CrossRef]

78. Moran, D.J. ACT for leadership: Using acceptance and commitment training to develop crisis-resilient change managers. Int. J. Behav. Consult. Ther. 2011, 7, 66-75. [CrossRef]

(C) 2020 by the authors. Licensee MDPI, Basel, Switzerland. This article is an open access article distributed under the terms and conditions of the Creative Commons Attribution (CC BY) license (http://creativecommons.org/licenses/by/4.0/). 